\title{
Cytotoxic effect of Leurius quinquestratus (scorpion) venom in different human cancer cell lines in vitro
}

\author{
Wesam M Salama*, Sabry A El-Naggar \\ Zoology Department, Faculty of Science, Tanta University, Tanta, Egypt \\ *For correspondence: Email: wesam.hassan@science.tanta.edu.eg; Tel: +20-01200355329 \\ Sent for review: 18 August 2020 \\ Revised accepted: 18 January 2021
}

\begin{abstract}
Purpose: In this study, the cytotoxicity of scorpion Leurius quinquestratus crude venom (LQCV) was evaluated in vitro in selected human cancer cell lines.

Methods: Breast (MCF-7), hepatocellular (HepG-2), colon (CaCo-2), cervix (HeLa) and alveolar (A-549) adenocarcinoma cell lines were tested. MTT assay and median inhibition concentration (IC50), apoptotic assay, caspase 3, P53, Bcl-2 proteins and cell cycle were determined.

Results: 24 hrs post-treatment, CaCo-2 represented the most sensitive cell line (IC 50 of $4.12 \mu \mathrm{g} / \mathrm{mL}$ ). Due to the exposure to $1 / 10 I C_{50}$ of $L Q C V$, the percentage of the apoptotic cells, caspase 3 , and P53 proteins were increased significantly $(P<0.05)$ while $B c l-2$ was decreased in comparison to untreated cells. Treatment with LQCV induced cell cycle arrest at G1 and G2/M phases.

Conclusion: LQCV displays potent cytotoxicity against selected human cell lines in vitro. Thus, the material could become a potent agent for the management of some cancers.
\end{abstract}

Keywords: Apoptosis, Cytotoxicity, Cancer, Cell cycle, Leiurus quinquestratus, Scorpion venom

\begin{abstract}
This is an Open Access article that uses a fund-ing model which does not charge readers or their institutions for access and distributed under the terms of the Creative Commons Attribution License (http://creativecommons.org/licenses/by/4.0) and the Budapest Open Access Initiative (http://www.budapestopenaccessinitiative.org/read), which permit unrestricted use, distribution, and reproduction in any medium, provided the original work is properly credited.

Tropical Journal of Pharmaceutical Research is indexed by Science Citation Index (SciSearch), Scopus, International Pharmaceutical Abstract, Chemical Abstracts, Embase, Index Copernicus, EBSCO, African Index Medicus, JournalSeek, Journal Citation Reports/Science Edition, Directory of Open Access Journals (DOAJ), African Journal Online, Bioline International, Open-J-Gate and Pharmacy Abstracts
\end{abstract}

\section{INTRODUCTION}

Venom toxins are secretions that are produced from invertebrate and vertebrate animals. Necrotoxins, cytotoxins, neurotoxins and myotoxins are considered the major classes of venom. Invertebrates have a lot of venomous animals such as jellyfish sea anemone, corals, spider, scorpion, sea urchin and some types of octopus [1]. Scorpions are predatory venomous invertebrates that belong to the phylum Arthropoda, sub phylum Chelicerata, class Arachnida order Scorpionidea [2].
Scorpion's venom consists of a mixture of enzymes, peptides, mucoproteins, lipids, nucleotides, and biogenic amines [3]. Scorpion's venom has different effects such as neurotoxins, enzyme inhibitor, hemolytic toxins and antibacterial activities [4]. Active compounds that are isolated from scorpion's venom, such as iberitoxin, margatoxin, and charybdotoxin were found to have antiproliferative effects against cancer cell lines [5]. Leiurus quinquestratus (Deathstalker) is mainly distributed in Egypt and belongs to the family Buthidea [2]. Leiurus quinquestratus crude venom (LQCV) contains polypeptides that block or change the properties of ion channel gates with low molecular weight 
protein [6]. Interestingly, LQCV has numerous compounds that affect cancer cells, for instance, charybdotoxin-2 (Lqll), a-toxin Lqll and chlorotoxin. Treatment with LqIII and chlorotoxin led to slowing the inactivation of $\mathrm{Na}$ channels and inhibiting chlorine ion conductance expressed by glioma cells [7].

For cancer treatments, different approaches were applied as a conventional chemotherapy, radiation, immunotherapy and gene therapy. Even though chemotherapy is the best choice for cancer treatment post-surgery, it causes severe side effects on normal tissues [8]. To destroy cancer cells without harming normal tissues, several efforts to find new bioactive compounds were tested in the last few years [9]. Scorpion's venom has been examined as anticancer on various cancer types such as lymphoma, neuroblastoma, lung, prostate and pancreatic cancer [10]. A previous study showed that the treatment with scorpion's venom inhibited cancer metastasis and caused cell cycle arrest [11]. This study aimed to evaluate the cytotoxic effect of LQCV against five different human cell lines; breast (MCF-7), hepatocellular (HepG-2), colon (CaCo-2), cervix (HeLa) and alveolar (A-549) adenocarcinoma cell lines in vitro.

\section{EXPERIMENTAL}

\section{Human cancer cell lines}

Human breast adenocarcinoma (MCF-7), hepatocellular adenocarcinoma (HepG-2), colon colorectal adenocarcinoma (CaCo-2), alveolar adenocarcinoma (A-549) and cervix adenocarcinoma (HeLa) cell lines were purchased from the American Type Culture Collection (ATCC, Rockville, MD, USA). These cells were transferred to the regional Center for Mycology and Biotechnology, Al-Azhar University, and preserved in a liquid nitrogen tank $\left(-170^{\circ} \mathrm{C}\right)$ until being used. Cancer cell lines were authenticated using a standard method and were tested to detect the mycoplasma infection by using the mycoplasma kits.

\section{Sample collection and venom preparation}

Leiurus quinquestriatus scorpions were collected by professional hunters from Aswan, South Egypt, in July 2018 (Figure 1). Specimens were collected in plastic containers and transferred to the central lab, Zoology Department, Tanta University, Egypt, and were fed with cockroaches and water ad libitum. Venom was collected and lyophilized in Corporate Serum and Vaccine (VACSERA), Dokki, Cairo, Egypt. Different concentrations were prepared from the lyophilized venom.

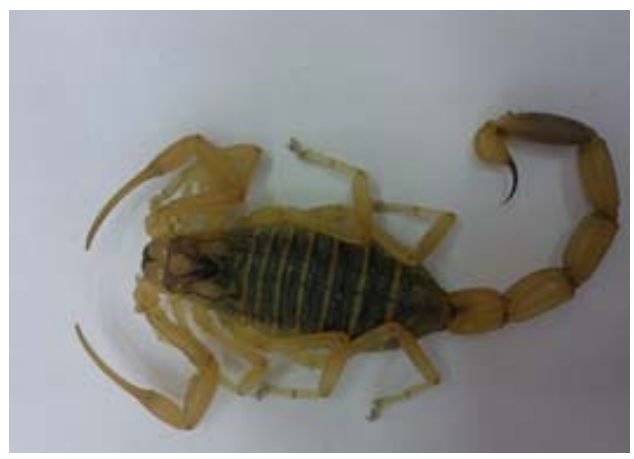

Figure 1: Dorsal view of scorpion L. quinquestratus

\section{Reagents}

Doxorubicin (Dox), dimethyl sulfoxide (DMSO) and (3-(4,5-Dimethylthiazol-2-yl) 2,5diphenyltetrazolium bromide (MTT), a tetrazole) and trypan blue were purchased from Sigma (St Louis, Mo, USA). Fetal Bovine serum, RPMI1640, L-glutamine, gentamycin and $0.25 \%$ Trypsin-EDTA were purchased from Lonza (Belgium). Annexin V (FITC, Becton Dickinson BD Pharmingen ${ }^{\mathrm{TM}}$, Heidelberg, Germany). Propodeum iodide/Ribonuclease staining buffer (Cell Cycle Detection Kit, Signalway Antibody (SAB) Co. Ltd). Lysis buffer and phosphate buffer saline (PBS) were purchased from Roche Molecular Biochemicals. Primary antibodies for $\mathrm{P}_{53}$, Bcl-2 and caspase-3 were obtained from Signaling Technology (Beverly, CA, USA).

\section{In vitro cytotoxic assay}

MTT assay was used; briefly, cancer cells were grown on RPMI-1640 media supplemented with $10 \%$ fetal calf serum and $50 \mu \mathrm{g} / \mathrm{mL}$ gentamycin at $37{ }^{\circ} \mathrm{C}$ in a humidified chamber with $5 \% \mathrm{CO}_{2}$ [12]. For the antitumor assay, three replicas of twelve concentrations of LQCV and reference drug (Dox) were suspended in $0.5 \%$ DMSO for $24 \mathrm{hr}$. Optical density (OD) was measured at 590 $\mathrm{nm}$ after the exposure for $24 \mathrm{hr}$ (Sunrise, TECAN, Inc, USA). Half maximal inhibitory concentration $\left(\mathrm{IC}_{50}\right)$ was calculated using Graphed Prism software (San Diego, CA, USA).

\section{Apoptosis assay}

To determine the apoptotic cells, CaCo- 2 cells were cultured in 6 well plates and then they were treated with $1 / 10 \mathrm{IC}_{50}$ of LQCV $(0.412 \mu \mathrm{g} / \mathrm{mL})$ for $24 \mathrm{hr}$. After that, they were harvested and rinsed twice in PBS, followed by the binding buffer. A million of Caco-2 cells were resuspended in 100 $\mu \mathrm{L}$ of binding buffer, then $1 \mu \mathrm{L}$ of FITC-Annexin 
VI PI (propidium iodide) was added and incubated at $4{ }^{\circ} \mathrm{C}$ for 40 mins. Cells were then washed and resuspended in $150 \mu \mathrm{L}$ of the binding buffer with the addition of $1 \mu \mathrm{L}$ of DAPI (1 $\mu \mathrm{g} / \mathrm{mL}$ ). Finally, the cells were analyzed using the flow cytometer BD FACS Calibur (BD Biosciences, San Jose, CA).

\section{Caspase-3, $\mathrm{P}_{53}$ and $\mathrm{Bcl}-2$ protein expression}

The expression levels of caspase $3, \mathrm{P}_{53}$ and $\mathrm{Bcl}-$ 2 were detected. In brief, control and treated CaCo-2 cells were suspended in lysis buffer. Then the cytosolic and nuclear proteins were isolated. Protein was separated using $8 \%$ SDSPAGE and then incubated with specific primary antibodies at $1: 1,000$ dilution for $2 \mathrm{hr}$ on nitrocellulose membrane. The membrane was washed three times with tris buffer, and then it was incubated with secondary antibodies. The blot in each case was developed using an enhanced chemiluminescence (ECL system; Amersham Pharmacia Biotech, Piscataway, NJ, USA).

\section{Cell cycle analysis}

Cell cycle analysis was determined as described according to Weir et al. [27]. CaCo- 2 cells $(2 \mathrm{x}$ $10^{4}$ ) were seeded and treated with $1 / 10$ IC 50 of LQCV or dox for $24 \mathrm{hr}$. Cells were harvested and fixed overnight in $70 \%$ cold ethanol at $4{ }^{\circ} \mathrm{C}$. After washing with ice-cold PBS, the fixed-cell pellets were collected by centrifugation and resuspended in $\mathrm{PI} / \mathrm{RNase}$ staining Buffer, then analyzed on a flow cytometer (FACSAriaTM III). Cell-cycle was calculated using CELLQUEST software (Becton Dickinson Immunocytometry Systems, San Jose, CA).

\section{Statistical analysis}

Data were presented as mean \pm SD and were analyzed using one-way analysis of variance (ANOVA) followed by Dunnet test and $p<0.05$ or $p<0.01$ were statistically significant.

\section{RESULTS}

\section{Cytotoxicity of LQCV against human cell lines}

Cytotoxicity of LQCV was evaluated against 5 human cancer cell lines using different concentrations of LQCV. Doxorubicin was used as a reference drug at the same concentrations. The results showed that treatment with LQCV significantly reduced the viability of cancer cell lines in a dose-dependent manner. The median inhibition concentration $\left(\mathrm{IC}_{50}\right)$ of the LQCV on MCF-7, HepG-2, CaCo-2, A-549 and HeLa were
$8.86 \pm 0.7,7.77 \pm 0.3,4.12 \pm 0.2,14.3 \pm 1.2$ and $23.1 \pm 2.7 \mu \mathrm{g} / \mathrm{mL}$, respectively. Interestingly, CaCo-2 was the most sensitive cell line to the LQCV (Figures 2 and 3).

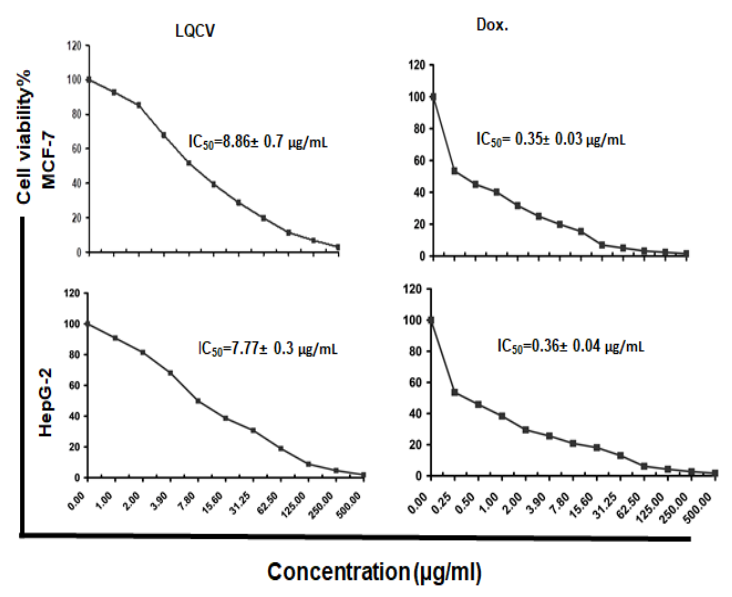

Figure 2: The $\mathrm{IC}_{50}$ of MCF-7 and HepG-2 post-24 hr exposure to different concentrations of LQCV and Dox

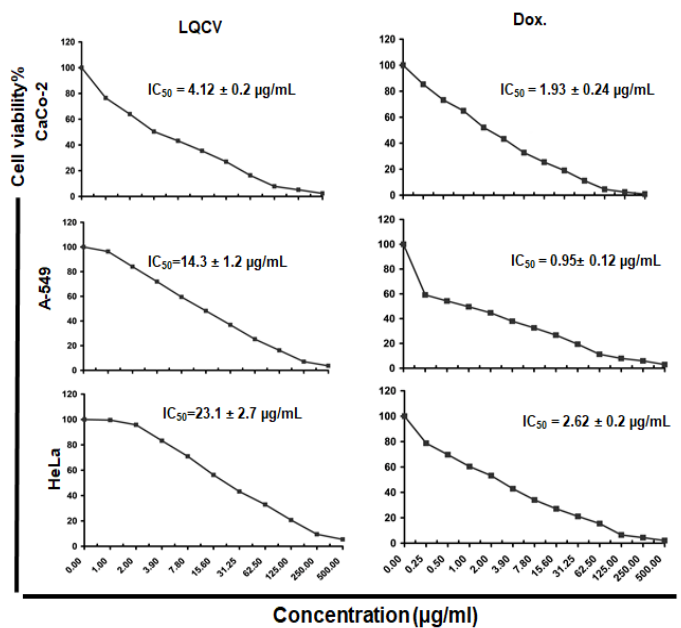

Figure 3: The $\mathrm{IC}_{50}$ of CaCo-2, A549 and HeLa post $24 \mathrm{~h}$ exposure to different concentrations of LQCV and Dox

\section{Apoptosis}

$1 / 10 I_{50}$ of both LQCV and Dox were used on the CaCo-2 cell line. Treatment with $1 / 10 I_{50}$ of LQCV increased the percentage of early apoptosis significantly from $0.88 \%$ to $7.89 \%$. A significant increase in the percentage of late apoptosis from 0.24 to $16.75 \%$ was noticed. Treatment with $1 / 10 I_{50}$ of Dox $(0.193 \mu \mathrm{g} / \mathrm{mL})$ increased early and late apoptosis percentage from 0.88 to $8.24 \%$ and from 0.24 to $9.74 \%$, respectively. The percentage of necrotic cells after LQCV and Dox treatment was 2.72 and $3.81 \%$ correspondingly (Figure 4 ). 


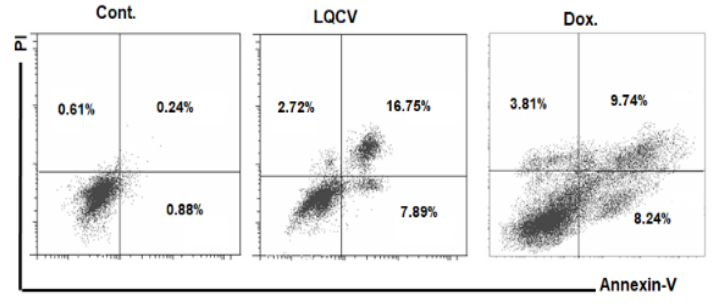

Figure 4: Apoptosis (\%) of CaCo-2 cell lines post-24 h exposure to $1 / 10 I_{50}$ of LQCV and Dox

\section{Caspase 3, $\mathrm{P}_{53}$ and $\mathrm{Bcl}-2$ proteins expression}

Caspase 3 and $P_{53}$ protein levels were increased, while a marked decrease in antiapoptotic protein $\mathrm{Bcl}-2$ post-treatment with 1/10 $\mathrm{IC}_{50}$ of both LQCV and Dox (Figure 5).

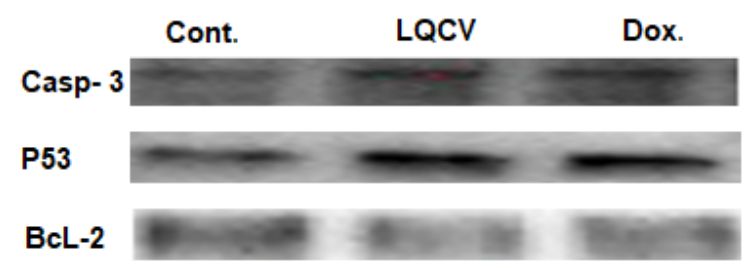

Figure 5: Caspase-3, $\mathrm{P}_{53}$ and $\mathrm{Bcl}-2$ proteins expressions in CaCo-2 cell line post $24 \mathrm{hrs}$ exposure to $1 / 10$ IC 50 of LQCV and Dox

\section{Cell cycle analysis}

There was a significant increase in G0, G1 and G2/M phases in the CaCO-2 cell line due to the treatment with $1 / 10 \mathrm{IC}_{50} \mathrm{LQCV}$. A similar pattern was noticed after the treatment with Dox (Figure $6)$.

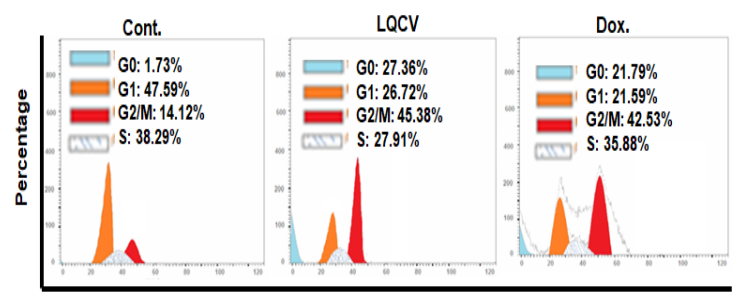

Figure 6: Cell cycle analysis of CaCo-2 cell lines post$24 \mathrm{hrs}$ exposure to $1 / 10$ IC 50 of LQCV and Dox

\section{DISCUSSION}

Different treatment settings are applied to treat cancer, such as surgery, chemotherapy, radiotherapy and immunotherapy [8]. Conventional chemotherapy induces hepatotoxicity and nephrotoxicity [13]. To overcome its side effects, natural products derived from animals or plants have been investigated as a safe alternative approach for cancer treatment [14]. In this line, an investigation of the antitumor effect of LQCV on 5 different cancer cell lines in vitro was conducted in this study. LQCV showed potential cytotoxicity against different human cancer cell lines.

Consistent with this finding, Abdel Aziz et al [15] reported the cytotoxic effect of LQCV on MCF-7 and $\mathrm{CaCo}-2$ cell lines. The data showed that the CaCo- 2 cell line was the most sensitive cell line after $24 \mathrm{~h}$ of treatment with LQCV. These data are contra directory to those achieved by Abdel Aziz et al [15], who revealed that MCF-7 was more sensitive than CaCo-2 cell line after being exposed to LQCV in vitro. Few studies previously represented that LQCV showed cytotoxic effects against breast cell line (T47D) and low toxicity against prostate cancer cell lines (DU145, PC-3 and TSUpr1) [11]. Similarly, the cytotoxic effect of $L$. quinquestratus and $A$. crassicauda crude venoms were tested against breast (MDA-MB231) and colorectal cell lines (HCT-8) [16].

To understand the cytotoxic effect of LQCV, apoptosis, cell cycle arrest, caspase $3, \mathrm{Bcl}-2$ and $\mathrm{P}_{53}$ protein were analyzed $24 \mathrm{hrs}$ post-treatment. The ability of LQCV to induce necrosis, apoptosis and cell cycle arrest to cancer cell lines revealed its potent cytotoxicity. The tested LQCV has an antiproliferation effect on $\mathrm{CaCo}-2$ cells growth by apoptosis. An increase in early apoptotic and late apoptotic CaCo-2 cells after 24 hrs of incubation with LQCV was noticed. LQCV stimulated the activation of $\mathrm{P}_{53}$ that induced the anti-apoptotic protein Bcl-2 in order to be decreased. These findings are in agreement with the previous study on the crude venom of scorpion Buthus martensi, A. amoreuxi and L. quinquestratus [17]. Similar studies revealed that Odontobuthus doriae, A. amoreuxi and $A$. crassicauda venom inhibited cell growth and increased caspase 3 expression and activation in breast and neuroblastoma cell lines with DNA fragmentation [18].

Cell cycle arrest of CaCo-2 under the effect of LQCV was evaluated. A similar finding showed that $A$. crassicauda venom arrested S-phase and induced apoptosis [19]. The cytotoxic effect of LQCV was very close to the cytotoxicity under the effect of Dox. LQCV causes apoptosis or necrosis by binding to a membrane or blocking an ion channel, causing DNA damage and oncogene activation, affecting the intrinsic or mitochondrial pathway [20]. Hence, the elevation of $\mathrm{P}_{53}$ protein that induced the decrease of $\mathrm{Bcl}-2$ could stimulate mitochondrial gene, cytochrome $c$ to liberate in the cytosol where it activates caspase 9.

\section{CONCLUSION}

Trop J Pharm Res, February 2021; 20(2): 348 
Leiurus quinquestratus crude venom (LQCV) exerts a strong cytotoxic effect against five human cancer cell lines in vitro. LQCV increases the level of apoptotic CaCo-2 cells, enhances the expression of caspase 3 and $P_{53}$, but decreases $\mathrm{Bcl}-2$ protein expression. Thus, LQCV is potentially a potent anticancer agent, however, further studies are required to ascertain this.

\section{DECLARATIONS}

\section{Acknowledgement}

The authors thank Cell Culture Department VACSERA, Giza, Egypt, for their help during this study.

\section{Conflict of interest}

The author declares that there is no conflict of interest.

\section{Contribution of authors}

We declare that this work was done by the author(s) named in this article, and all liabilities pertaining to claims related to the content of this article will be borne by the authors. All authors read and approved the manuscript for publication. Wesam M. Salama conceived, designed the study, and wrote the manuscript, whereas Sabry A. El-Naggar collected and analyzed the data. All the authors read and approved the manuscript.

\section{Open Access}

This is an Open Access article that uses a funding model which does not charge readers or their institutions for access and distributed under the terms of the Creative Commons Attribution License (http://creativecommons.org/licenses/by/ 4.0) and the Budapest Open Access Initiative (http://www.budapestopenaccessinitiative.org/rea d), which permit unrestricted use, distribution, and reproduction in any medium, provided the original work is properly credited.

\section{REFERENCES}

1. Bonamonte D, Gianni A. Aquatic Dermatology: Biotic, Chemical and Physical Agents. 2nd edition. Springer International. 2016, pp 54-56.

2. Lourenco $W$, The scorpion families and their distribution of noxious species of scorpion (Arachnida: Scorpiones).

J. Venom Anim. Toxins incl. Trop. Dis., 2018. 24 (1): 323.
3. Diego-García E, Batista CV, García-Gómez Bl, Lucas S, Candido DM, Gómez-Lagunas F, Possani LD. The Brazilian scorpion Tityus costatus Karsch: genes, peptides and function. Toxicon, 2005. 45(3): 273-283.

4. Salama W, Geasa N, Investigation of the antimicrobial and hemolytic activity of venom of some Egyptian scorpion. J. Microbiol. Antimicrob. 2014. 6(1): 21-28.

5. Mobli M, Undheim E, Rash DL, Modulation of Ion Channels by Cysteine-Rich Peptides: From Sequence to Structure. Adv. Pharmacol, 2017. 79: 199-223.

6. Salama $W$, Sharshar $K$, Surveillance study on scorpion species in Egypt and comparison of their crude venom protein profiles. J. basic and appl. Zool, 2013. 66:76-86.

7. Beeton C, Targets and Therapeutic Properties. Handbook of biologically active peptides. 2nd edition, chapter 64. 2013. 473-482.

8. Dagogo-Jack I, Shaw AT, Tumour heterogeneity and resistance to cancer therapies. Nat Rev Clin Oncol, 2018, 15(2):81-94.

9. Bokemeyer C, Berger CC, Hartmann JT, Kollmannsberger C, Schmoll HJ, Kuczyk MA, kanz L, Analysis of risk factors for cisplatin-induced ototoxicity in patients with testicular cancer. Br. J. Cancer, 1998. 77: 1355-1362.

10. Omran, $M$, In vitro anticancer effect of scorpion Leiurus quinquestriatus and Egyptian cobra venom on human breast and prostate cancer cell lines. J. Med. Sci, 2003. 3: $66-86$.

11. Ding J, Chua PJ, Bay BH, Gopalakrishnakone $P$, Scorpion venoms as a potential source of novel cancer therapeutic compounds. Exp Biol Med (Maywood), 2014, 239(4):387-393.

12. Kumar $P$, Nagarjan A, Uchil $P$, Analysis of Cell Viability by the MTT Assay. Cold spring Harb Protoc, 2018. 1(6), doi:10.1101/pdb.prot095505.

13. Gupta SD, Gomes A, Debnath A, Saha A, Gomes A, Apoptosis induction in human leukemic cells by a novel protein Bengalin, isolated from Indian black scorpion venom: through mitochondrial pathway and inhibition of heat shock proteins. Chem. Biol. Interact, 2010. 183(2): 293-303.

14. Weir NM, Selvendiran $K$, Kutala VK, Tong $T$, Vishwanath S, Rajaram M, Tridandapani S, Anant S, Kuppusamy $P$, Curcumin induces G2/M arrest and apoptosis in cisplatin-resistant human ovarian cancer cells by modulating Akt and p38 MAPK. Cancer Biol Ther, 2007. 61:78-184.

15. Abdel-Aziz SA, Mohamed AF, Zahkouk SA, Ali RA, Evaluation of anticancer activity of some venomous animal toxins on human breast and colon cancer cell lines and related antioxidant profile. Int. J. Adv. Res, 2017. 5(2): 2036-2053.

16. Al-Asmari AK, Riyasdeen A, Islam M, Scorpion Venom Causes Apoptosis by Increasing Reactive Oxygen Species and Cell Cycle Arrest in MDA-MB-231 and HCT-8 Cancer Cell Line. Journal of Evidence-Based Integrative Medi, 2018. 23: 1-8

Trop J Pharm Res, February 2021; 20(2): 349 
17. Zhang $Y Y$, Wu LC, Wang $Z P$, Wang $Z X$, Jia $Q$, Jiang GS, Zhang WD, Antiproliferation effect of polypeptide extracted from scorpion venom on human prostate cancer cells in vitro. J. Clin. Med. Res, 2009. 1(1): 2431.

18. Zargan J, Sajad M, Umar S, Naime M, Ali S, Khan HA, Scorpion (Androctonus crassicauda) venom limits growth of transformed cells (SH-SY5Y and MCF-7) by cytotoxicity and cell cycle arrest. Exp Mol Pathol, 2011. 91: 447-454.

19. Wang $X$, The expanding role of mitochondria in apoptosis. Genes. Dev, 2001.15: 2922-2933.

20. Lin W, Xin J, Xue N, Huang L, Xu A, Li H, Li C, Gao Y, Watanabi $M$, Liu Ch, et al., Glaucocalyxin $A$ induces G2/M cell cycle arrest and apoptosis through the PI3K/Akt pathway in human bladder cancer cells. Int. J. Biol. Sci, 2018. 14(4): 418-426. 